\title{
Virtual laboratory methodologies in electrical engineering
}

\author{
María Isabel Jiménez Gómez, Alberto Izquierdo Fuente, \\ Juan José Villacorta Calvo, \\ Lara del Val Puente and Mariano Raboso Mateos \\ University of Valladolid \\ Spain
}

\section{Introduction}

Every engineering student must develop an MSc Thesis to finish their studies and obtain the corresponding degree. This work is a project that consists in a semi-professional work, managed, guided and supervised by at least one teacher from their university.

In electrical engineering, there are some MSc Thesis themes that have to be developed in the laboratory at the university, because of the technical materials the project needs. So the students must go to the research laboratory, because the hardware media they need are only available at the university. But many times these displacements to the university can be very difficult, even impossible, for the students. Since some years ago, there is an increment of the percentage of students who are finishing their studies at the same time they have just begun working in a company. So, it is very often that students who ask for an MSc Thesis to finish their studies, also they are working in a company yet, and they need to know how they can do both of them. Moreover, the opening hours of the university, where the laboratory is, limit too much the time that the students have the laboratory really opened to work (Cedazo et al., 2005).

To solve this problem, it is provided a new way of developing of the MSc Thesis in a remote way by the students without impacting on the technical nature of the projects or the quality of them. The offered projects to electrical engineering students are included in digital signal processing area. For this, it is proposed the design, implementation and application of a system that allows the students to work at home with the devices installed in the university laboratory. Virtual laboratory allows working in a remote way, from a computer at home that connects via Ethernet to the laboratory devices, and via web for viewing and analyzing the results that are obtained. This way solves the difficulties of working physically in the technical laboratories, either by incompatible opening hours, few available computers or work responsibilities of the students.

The system is formed by the personal computer that the students use to work at home, and the physical devices in the laboratory that they use to perform the experiments. The assessment of the students' work is made by their tutor teacher, using electronic mailing, as a remote management. 
It is shown the whole work of design and installation in the laboratory, the analysis and selection of the hardware and software, the work methodology, the project development evolution and the obtained results. Finally, it can be seen the advantages and conclusions of this work. This is a new way to apply teaching tools in order to improve technical university teaching. And also, this way allows the students to do their MSc Thesis with more maturity and efficiency.

\section{Goals}

There are authors who have been working with virtual laboratories based on web. These virtual laboratories are as virtual tool and as virtual features and methodologies, because they use web platform and services, and they work with software that simulates the real laboratory performance (Cedazo et al., 2007).

In this case, we present virtual laboratory systems that allow working with real tools and systems, via web from another place, but the tests and obtained results are realized in a real laboratory.

The main goal achieved with this work has been undoubtedly to provide a new way of developing of the MSc Thesis in a remote way by the students without impacting on the technical nature of the projects or the quality of them.

This technique is exposed to apply for any MSc Thesis that can be realized to obtain the electrical engineering degree. As example, it is shown the case of one whose aim is implementing an array to find acoustic sources to apply for room acoustics, over National Instruments hardware and developed in LabView (Kuttruff, 2000).

It is also attempted students do their project with more autonomy, being more decisive for themselves, which provides them with an added quality for their future jobs.

This way has proposed to reduce the giving-up and delay rates for finishing the engineering studies too. It is a logic consequence of the item exposed before. That is because being university teachers make us feel responsible of engineers learning to the end of their studies, so they reach their goals.

Finally, the technique proposes to measure, in the best way, the goodness and advantages of this virtual laboratory system for further applied to other MSc Thesis, research works and subjects of another nature, that need to work with other students and colleagues from different universities.

\section{Problem formulation}

Since some years ago, there is an increment of the percentage of students who are finishing their studies and also working in a company. While jobs offer is not very good for electrical engineers, in general, there are a great number of practices for university students, which allow them to get their first work, and even it is paid very often. So, it is not unusual that students who ask us for a MSc Thesis, also they talk about the work they are making in a company and how they can do both of them (Esteban \& Martínez, 2006).

For all these reasons, we have thought that these students need a solution to their handicap, to make them finish their studies as the other students, but without decreasing the goals they have to achieve. 
It was realized a study and analysis of these students' profile, and we noticed their high motivation in working without having completed their studies, so it would influence in a high motivation to finish their studies, because as engineers they have an improvement in their conditions of contract and salary.

In addition, the students who are working in a company give us a guarantee of their responsibility and maturity, because they are developing real objectives, so they are going to be able to do the project in the best way.

There are also cases of students who can not develop the project 'in situ' in the laboratory, but their reasons are different of being working. Their reasons use to be personal or family issues or perhaps they live far away from the university, and they can not go to university very often. These students, as the others, need a solution that helps them to finish their studies too.

For all those cases, there are enough students who need more scheduling flexibility because they have not too much time to do their MSc Thesis. For this, it is proposed a system and a working methodology that allow them working at home, thanks to this virtual laboratory. But, in the laboratory or not, the project must be well done during the hours required.

Therefore, it is exposed a working methodology to realize the MSc Thesis in a feasible way for engineering students who have not time or possibilities for working in the university laboratories.

\section{Solution to the problem and methodology: virtual laboratory}

It is provided a solution that consists in the design of a teaching strategy to work with the devices and hardware in the research laboratory at university and to offer scheduling flexibility, because the work with the laboratory material is made from a place out of the university.

Therefore, the strategy was a formal assembly and installation of devices to enable the student from his computer at home, connected to the internet, to access to the system in the laboratory. Once designed and implemented the system, it is performed some tests to make sure it works properly. And then, the tutor teacher meets with the student to explain the system and how it works and operates, and also, he shows him the methodology and means he is going to use to make his MSc Thesis.

The teacher gives him, like any other student, all the specifications and objectives of the electrical engineering project to get the MSc Thesis, as well as the guidelines and the theory, and relevant documentation. He also provides him the software that should be installed on his computer, and the keys and corresponding protocols to connect to the hardware in the laboratory, by internet, and also to the webcam via web.

Thus, it is called this teaching strategy "virtual laboratory", referring to a methodology of work consisting in access to a real laboratory located in a place (university) from outside the laboratory, from a different place, and usually far away from it. It is really a laboratory, because the student works with the devices inside it, but at the same time, it is virtual, because the student does not work inside the laboratory.

The technical description of the project is not a goal of this chapter, because to use a virtual laboratory is independent of the application area. The specifications of this MSc Thesis allow applying the virtual laboratory to any engineering subject without problems. 
In this case the student should implement a real-time system based on an array of sensors in order to find acoustic sources. It consists in detecting the position of an acoustic source, finding its position based on its range and angle from the receiver. In reception it works with an array consisting of four sensors (microphones). The hardware of the project is a CompactRIO platform of National Instruments which has an FPGA accessed via a microprocessor. The student has programmed with LabView software. In figures 1 and 2 it can be seen the sensor array and the hardware platform where the programme developed by the student is executing (Naidu, 2001).

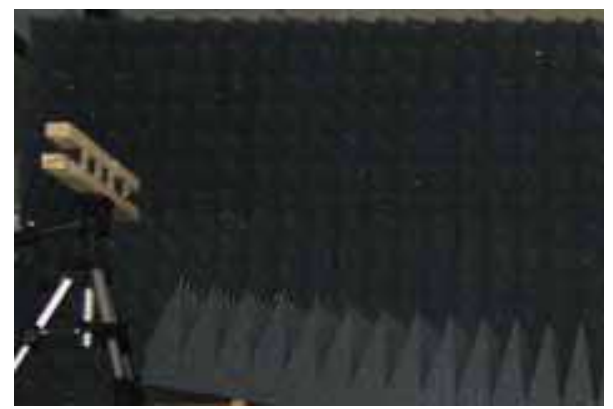

Fig. 1. Sensor array to find acoustic sources

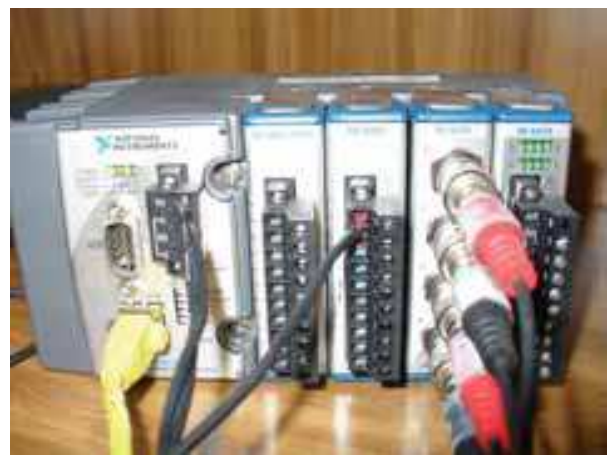

Fig. 2. CompactRIO Hardware of National Instruments

The acoustic sources used for all the tests are three types of sources. One of them has been the audio signal emitted by a speaker that has been generated with the same hardware that is used to receive, the second one is a voice recorded with an analogical device, and the third is a real conversation (Brandstein \& Ward, 2001).

While the student works at home with his computer, where the software that he uses has been installed (LabView), all the hardware of the project and its connections are in the university laboratory.

When the student makes his tests, he can also check the results that he is obtaining. The method consists in connect via web with a camera that is installed in the laboratory. The student can see, all the time, the results that he is obtaining in each test or experiment. These results are shown on the oscilloscope or device that shows the specific signal. He can check the right performance of his software or he can also correct the errors when he needs to. 
The hardware platform of the virtual laboratory system that has been implemented allows realizing data processing and visualization of virtual devices (oscilloscope, signal generator, etc.) in remote way. For this, the system has got a web camera for testing and visual control of the scenario and devices.

In figure 3 it can be seen the architecture of the virtual laboratory that has been proposed and performed.
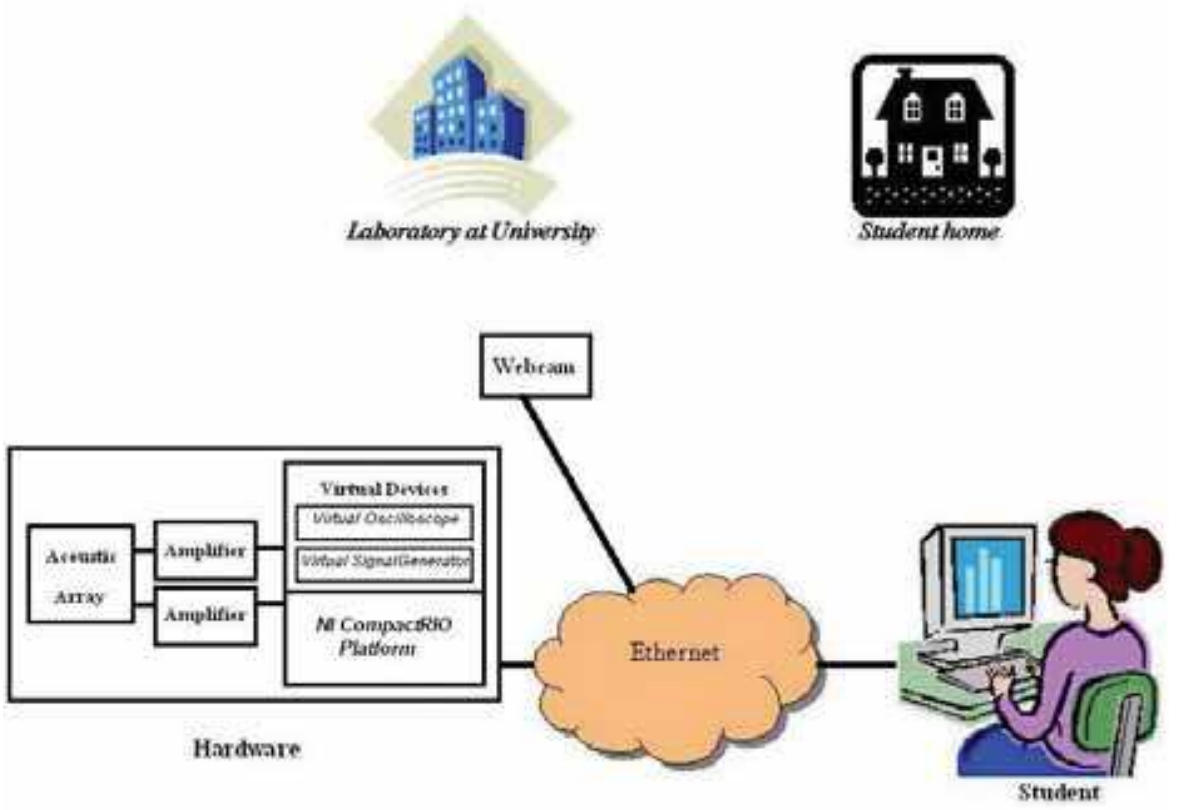

Fig. 3. Virtual laboratory architecture

The software of the system that is installed in the student's computer at home is: internet browser, LabView, text editor, etc; all the hardware that can be found in the university laboratory is: sensor array, speakers, pre-amplifier and amplifier, National Instruments hardware platform where the program is executed (via Ethernet), virtual devices to show the results (oscilloscope, signal generator, etc.) and webcam.

The students access to the hardware platform via Ethernet with a VPN (virtual private network) connection. This is an option that is provided by the university. Students can connect from everywhere to do their MSc Thesis by this way. The use of this connection is exclusively temporal. It is obligatory for students to ask for an authorization to their tutors to get this service. This service consists in a remote connection to the laboratory devices. The configured connection must guarantee advanced security with the encryption which is required.

Although this way of realization of the MSc Thesis by the student is a different way from the conventional one, the tutor's functions are the same as in other cases. These functions are: 
doing the description, giving the specifications, supervising the project and also answering all the questions that the student makes.

\section{Schedule of project activities}

In order to show the obtained results, we are based on the study of the work evolution of the students as well as the analysis of the follow-up that has been done by the tutors during the project.

In this case that it is exposed as reference, the student had a couple of meetings with his tutors at the beginning of his MSc Thesis. The first meeting was to describe and to explain the type of project that was proposed, and the second one was to expose all the technical specifications. Then, after answering all his questions, the student started working at home from his personal computer.

In the table 1 it is shown the schedule that was followed to realize the project using the described platform before.

\begin{tabular}{|c|c|}
\hline \multicolumn{2}{|c|}{ Schedule } \\
\hline Weeks & Activities \\
\hline Week 1 - Week 4 & Documentation, meetings and project objectives \\
\hline Week 5 - Week 7 & Specifications and testing of the virtual laboratory system \\
\hline Week 8 - Week 12 & First tests \\
\hline Week 13 - Week 17 & Experiments and results \\
\hline Week 18 - Week 22 & Analysis of results and conclusions \\
\hline Week 23 - Week 27 & Reporting and documentation of the whole project \\
\hline
\end{tabular}

Table 1. Schedule of project activities

The tutor teacher gave to the student all the specifications that he needed to do his work by e-mail. Thus, he learned how to install all the software on his computer, and how to connect to the laboratory hardware via Ethernet.

In order to view the results that have been obtained, the student connects to the laboratory webcam via internet from his computer. He has got specific software installed in his computer that allows him to view the results he is obtaining in every moment. This camera can be moved as its position and as its focus (zoom), for seeing the image with more detail.

There were three channels used for student-tutors communication: meeting to tutor teachers at university, electronic mailing and telephone calls.

The average results that have been obtained when the project finalized were:

Number of working hours during 6 month: 540 .

Number of questions asked for tutor teachers: 135.

Percentage of answers by meeting: $5 \%$.

Percentage of answers by e-mail: $90 \%$.

Percentage of answers by phone: $15 \%$.

The e-mail has been the main way that has been used to follow-up the project development. Most of the student's questions have been solved by e-mail. Also we have used a phone line to solve the questions that need longer or explicit arguments.

Also e-mail has been the way used by the student to send us all the results (tables, images, graphs, etc.) he has obtained. 
Both e-mail and telephone have been a great help for a speedy and effective communication between the student and tutors and they have been useful to follow-up the project.

For the student, it has been a success to be able to work following his own schedules at home, and also to develop a technical project with great autonomy.

The student has developed the goal of the project, and the large number of connections and exchanged information with the laboratory has been supported by the system without troubles, also because of the robust systems and the provided security.

In fact, the student has done their tests for a period of 6 months at a rate of about 4 hours a day. The system has supported all the connections, although many of them are long.

\section{Use case as example}

Now, we expose, as example, the graphic user interface developed with LabView. The case that can be seen is a localization of an acoustic source.

Some examples of the development and obtained results during the tests can be seen in figures 4 and 5 .

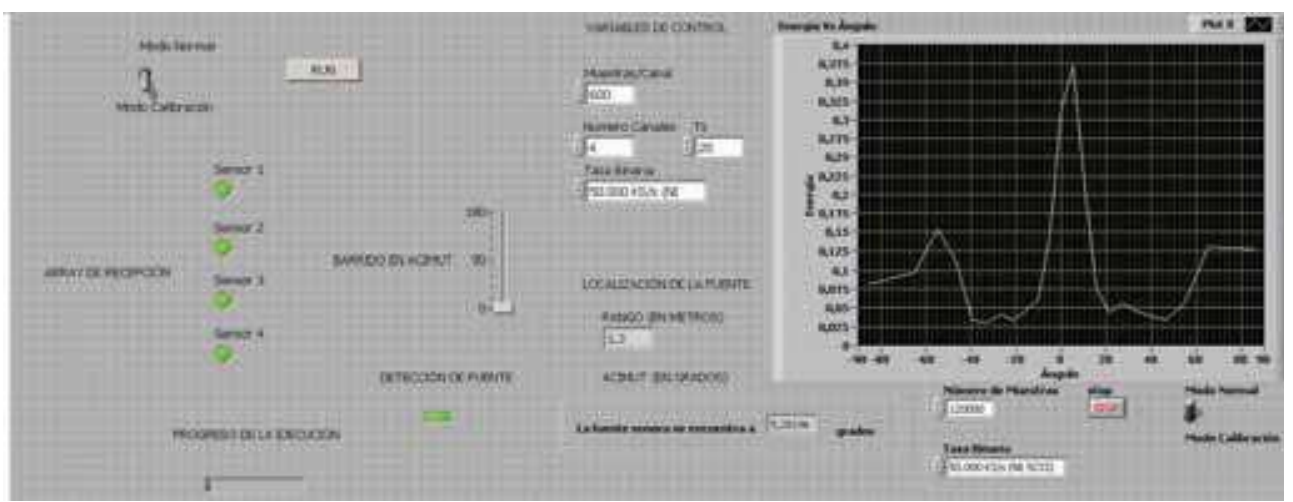

Fig. 4. Graphic user interface for localization of acoustic sources

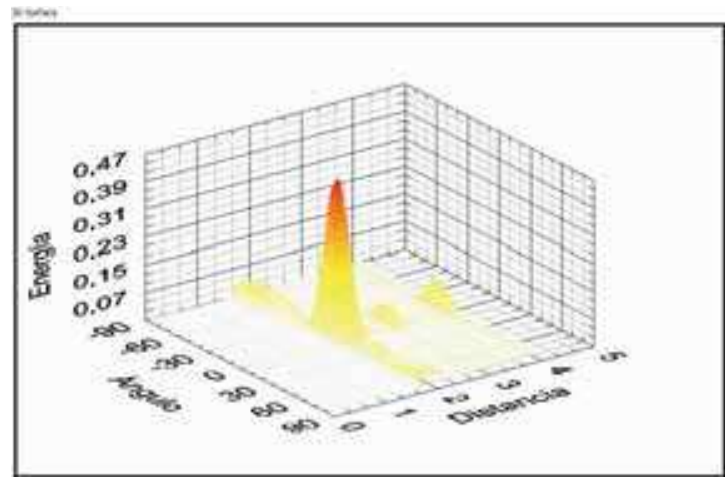

Fig. 5. Result of a localized acoustic source 
In the user interface it can be observed the parameters and characteristics whose values can be chosen or changed for getting the specific goals. When an acoustic source is localized, it is identified by the distance from de acoustic array to it, and also, by the angle with respect to broadside one. It can be seen in the three-dimension map that can be obtained with another interface developed with LabView too.

\section{Conclusions}

Under the students' viewpoint, they see the implementation of a project which has not been decreased in technical quality. In addition, they have worked with comfort, flexibility and motivation for a project with a methodology more open and on-line. It has really been a success for them to achieve their goals to become engineers.

We are pleased to achieve the realization of an electrical engineering MSc Thesis with a high level of autonomy by the students, using on-line media (very suitable for an electrical engineering project), that allows us to open a new way of projects implementation.

We have opened a new approach to do MSc Thesis pedagogically more efficient, that do not loose technical quality, and that affect the autonomy and maturity of students. These are skills that help them in their future jobs. Also these projects are more attractive than conventional projects for students.

It is important to know that this methodology mustn't be applied to subjects that don't need this type of system, because the obtained advantages are got only if the case requires it.

Finally, we also decide to use this methodology with colleagues to work together on some projects, between our universities and research laboratories. Also, this technique can be applied to other subjects of electrical engineering.

\section{References}

Brandstein, M. \& Ward, D. (2001). Microphone Arrays. Signal Processing Techniques and Applications, Springer-Verlag, ISBN 3-540-41953-5, Germany

Cedazo, R.; López, D.; Sánchez, F.M. \& Sebastián, J.M. (2007). Ciclope: FOSS for Developing and Managing Educational Web Laboratories. IEEE Transactions on Education, Vol. 50, No. 4, (November 2007) page numbers (352-359), ISSN 0018-9359

Cedazo, R.; Sánchez, F.M. \& Sebastián, J.M. (2005). CICLOPE ROBOT: a remote laboratory for managing an industrial robot in real time, Proceedings of International Conference on Engineering and Computer Education, ISBN 84-609-8149-9, Madrid, November 2005, ICECE05, Madrid

Esteban, L. \& Martínez, M. (2006). Guía del espacio europeo de educación superior, REIMAD, Madrid

Kuttruff, H. (2000). Room acoustics, Spon Press, ISBN 0-419-24580-4, USA \& Canada

Naidu, P.S. (2001). Sensor array signal processing, CRC Press, ISBN 0-8493-1195-0, USA 


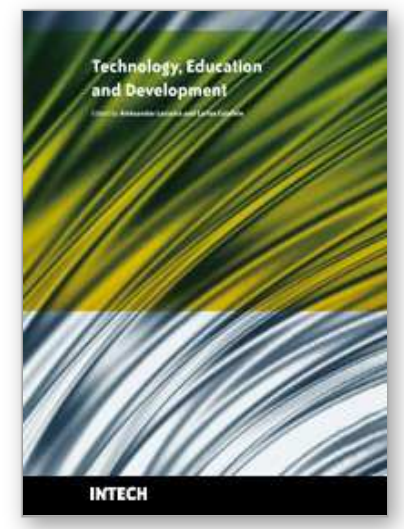

\author{
Technology Education and Development \\ Edited by Aleksandar Lazinica and Carlos Calafate
}

ISBN 978-953-307-007-0

Hard cover, 528 pages

Publisher InTech

Published online 01, October, 2009

Published in print edition October, 2009

The widespread deployment and use of Information Technologies (IT) has paved the way for change in many fields of our societies. The Internet, mobile computing, social networks and many other advances in human communications have become essential to promote and boost education, technology and industry. On the education side, the new challenges related with the integration of IT technologies into all aspects of learning require revising the traditional educational paradigms that have prevailed for the last centuries. Additionally, the globalization of education and student mobility requirements are favoring a fluid interchange of tools, methodologies and evaluation strategies, which promote innovation at an accelerated pace. Curricular revisions are also taking place to achieved a more specialized education that is able to responds to the society's requirements in terms of professional training. In this process, guaranteeing quality has also become a critical issue. On the industrial and technological side, the focus on ecological developments is essential to achieve a sustainable degree of prosperity, and all efforts to promote greener societies are welcome. In this book we gather knowledge and experiences of different authors on all these topics, hoping to offer the reader a wider view of the revolution taking place within and without our educational centers. In summary, we believe that this book makes an important contribution to the fields of education and technology in these times of great change, offering a mean for experts in the different areas to share valuable experiences and points of view that we hope are enriching to the reader. Enjoy the book!

\title{
How to reference
}

In order to correctly reference this scholarly work, feel free to copy and paste the following:

Maria Isabel Jimenez Gomez, Alberto Izquierdo Fuente, Juan Jose Villacorta Calvo, Lara del Val Puente and Mariano Raboso Mateos (2009). Virtual Laboratory Methodologies in Electrical Engineering, Technology Education and Development, Aleksandar Lazinica and Carlos Calafate (Ed.), ISBN: 978-953-307-007-0, InTech, Available from: http://www.intechopen.com/books/technology-education-and-development/virtuallaboratory-methodologies-in-electrical-engineering

\section{INTECH}

open science | open minds

\section{InTech Europe}

University Campus STeP Ri

Slavka Krautzeka 83/A

51000 Rijeka, Croatia

Phone: +385 (51) 770447

\section{InTech China}

Unit 405, Office Block, Hotel Equatorial Shanghai

No.65, Yan An Road (West), Shanghai, 200040, China

中国上海市延安西路65号上海国际贵都大饭店办公楼 405 单元

Phone: +86-21-62489820 
Fax: +385 (51) 686166

Fax: +86-21-62489821

www.intechopen.com 
(C) 2009 The Author(s). Licensee IntechOpen. This chapter is distributed under the terms of the Creative Commons Attribution-NonCommercial-ShareAlike-3.0 License, which permits use, distribution and reproduction for non-commercial purposes, provided the original is properly cited and derivative works building on this content are distributed under the same license. 